University of South Florida

DIGITAL COMMONS

Digital Commons @ University of

@ UNIVERSITY OF SOUTH FLORIDA

South Florida

April 1993

\title{
Characterization Of Karst Features Using Electromagnetics And Microgravity: A Strategic Approach
}

Lynn Yuhr

Richard Benson

Dwain Butler

Follow this and additional works at: https://digitalcommons.usf.edu/kip_talks

\section{Recommended Citation}

Yuhr, Lynn; Benson, Richard; and Butler, Dwain, "Characterization Of Karst Features Using Electromagnetics And Microgravity: A Strategic Approach" (1993). KIP Talks and Conferences. 33.

https://digitalcommons.usf.edu/kip_talks/33

This Conference Proceeding is brought to you for free and open access by the Karst Information Portal at Digital Commons @ University of South Florida. It has been accepted for inclusion in KIP Talks and Conferences by an authorized administrator of Digital Commons @ University of South Florida. For more information, please contact digitalcommons@usf.edu. 
By: Lynn Yuhr and Richard Benson

Technos, Inc., 3333 NW 21st Street, Miami, FL 33142

Dwain Butler

US Army Engineers - Waterway Experiment Station, 3909 Halls Ferry Rd., Vicksburg, MS 39180

\begin{abstract}
The flat-lying limestones of western Texas are naturally jointed with preferential dissolution occurring along joints and bedding planes. This area has some of the largest air-filled open caves in West Texas and large paleokarst collapse features have been identified throughout a wide region. Aerial photos indicate the presence of extensive joints, lineaments and paleokarst. Site characterization to detect and map such subsurface features using borings alone is inadequate to produce a reasonable level of spatial sampling. This paper addresses the application of surface geophysical techniques, and an assessment of the spatial sampling and instrument sensitivities necessary to define the karst features of interest in this geologic setting.

Electromagnetic measurements using a Geonics EM34 were selected because the measurements provide an excellent means of locating dissolution-enlarged joints. Microgravity was selected because it is the only surface geophysical method that will provide the location of karst feature regardless of their shape or fill material as long as there is a sufficient density contrast. While both methods have limitations, as do all methods of site characterization, the combination of gravity and EM measurements are complementary in this application.

A known cave system was used to establish the spatial sampling criteria for the detection and characterization of such features. Field tests were then run over two known karst sites; a paleokarst collapse; and a localized doline to provide anomaly signatures in this geologic setting.

It is clear that the EM and the gravity techniques are appropriate for detecting and characterizing karst features in this geologic setting. However, one of the key issues in planning and carrying out a geophysical survey, is developing a spatial sampling criteria. This criteria should be based upon an understanding of project objectives, a conceptual geologic model of site conditions and, if possible, existing data from the area of interest.
\end{abstract}




\section{GEOLOGIC SETTING}

The Stockton Plateau located in southwest Texas is characterized by relatively flat-lying limestone sequences. The limestone is generally massive and extends to depths of at least 1,000 feet or more. The water table occurs at 500 to 600 feet. Limestones in the region are known to contain dissolutioned-enlarged joints, paleokarst collapse and caves.

The Stockton Plateau contains the deepest caves in Texas and some of the longest (Fiseler, et al., 1978). Caves in this region extend to the water table at a depth of about 500 feet. The largest room in a known cave on the Stockton Plateau is about 100 feet in diameter. Extensive paleokarst collapse has been mapped by the United States Geological Survey (USGS) north of the Rio Grande river (Freeman, 1968). Based upon USGS findings, the origin of the paleokarst collapse is at a depth of about 250 to 300 feet. The displacement due to paleokarst collapse is as much as 250 feet.

The features of interest for site development are those which have undergone significant dissolution enlargement, such as vertical joints, zones of joints, paleokarst collapse and open cave systems. The normal "tight" joint systems are not generally of interest.

The presence of karst features are of concern for two reasons; the structural integrity of a site and ground water flow beneath and around the site. These two factors can impact site selection, the permit process, facility design, geotechnical remediation and ground water monitoring.

\section{APPROACH}

\section{Overall Strategy}

The accuracy and effectiveness of using borings to characterize subsurface conditions is heavily dependent upon the assumption that subsurface conditions are laterally uniform for a distance comparable to the average spacing between borings. In karst settings this is generally not true. Benson and Yuhr (1993) discuss the problem associated with site characterization in karst and suggest that subsurface investigation, by a limited number of borings alone, is like "looking for a needle in a haystack" and almost assures that the site characterization process will be incomplete or will meet with failure. Clearly there is a need for a different approach; not to replace borings, but to help locate anomalous areas to focus the borings in critical areas. 
A strategy was developed to detect and characterize any significant karst features at the proposed site, including dissolution-enlarged joints and cave systems. The general approach employed incorporated seven key steps:

1. aerial photo interpretation;

2. field reconnaissance to verify this aerial photo interpretation and to familiarize ourselves with the karst features previously identified by USGS and surface features not identified in the aerial photos or literature which may indicate the presence or condition of karst;

3. identify surface geophysical methods which can be used to locate and focus in on both significant fractures and karst and assess their spatial (horizontal and vertical) sampling and sensitivities necessary to define those karst features of interest;

4. carry out and interpret the surface geophysical measurements;

5. use selected borings to provide a further assessment of the anomalies identified by the geophysical methods;

6. use downhole geophysical logging to assess conditions within and around the borehole; and

7. if required, utilize hole to hole geophysics to assess fractures dissolution-enlarged fractures and cavities in three dimensions to any define remediation necessary if required.

This paper addresses the application of surface geophysical techniques and an assessment of the spatial sampling and instrument sensitivities necessary to define the karst features of interest in this geologic setting.

Benson and Yuhr (1993) provide a discussion of the spatial sampling capabilities for a wide range of geophysical methods. Most of the remote sensing and surface geophysical methods can be successfully applied to detecting or mapping fractures and cavities and/or to characterize their nature in one way or another. However, there is no single method that proves to be a "silver bullet" for all site characterization needs. The methods must be selected to fit the site conditions and project needs.

When discussing the detection of caves by geophysical methods, one often hears the question "how deep can you detect a cavity of such a diameter?". This is generally the wrong question, because it would bias the answer too shallow. The question should be phrased "how deep can you detect a cave system of given characteristics?" Estimates of the cavity detection capability of surface geophysical methods are often based upon simplistic isolated cavities as in Figure 1. These simple discrete models are often inappropriate, since such a singular feature is rarely found in nature. In fact, an enlarged room in any karst system will have at least one input and one output conduit leading to other portions of the cave system which likely also contains large rooms or conduits. 


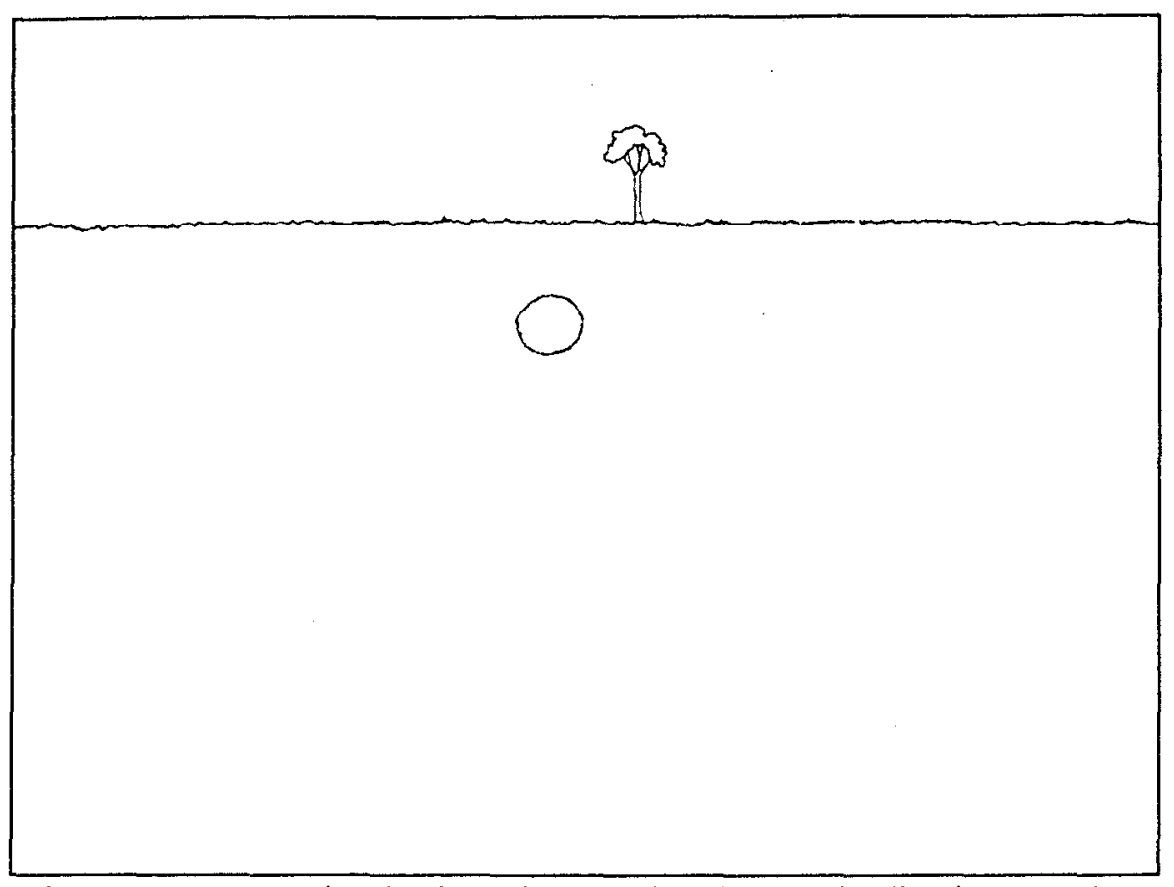

Figure 1. A spherical cavity can be theoretically detected at a maximum depth of a few time its diameter.

Early cavity detection literature has suggested that cavities could theoretically be detected at a depth no more than few times the "effective diameter" of the cavity (Figure 1) using methods such as gravity or resisitivity. However, three factors will generally enable us to detect cavities deeper than this "old" rule of thumb (Benson and Yuhr, 1993):

- First, karst systems rarely consist of isolated cavities such as shown in Figure 1;

- Second, rock strain, secondary permeability and/or chemical alterations often lead to a "halo" effect around the cavity effectively making it appear geophysically larger than it is (Figure 2); and

- Third, the associated network of dissolution-enlarged fractures, bedding planes and cavities involved with any cave system such as shown in Figure 3. 


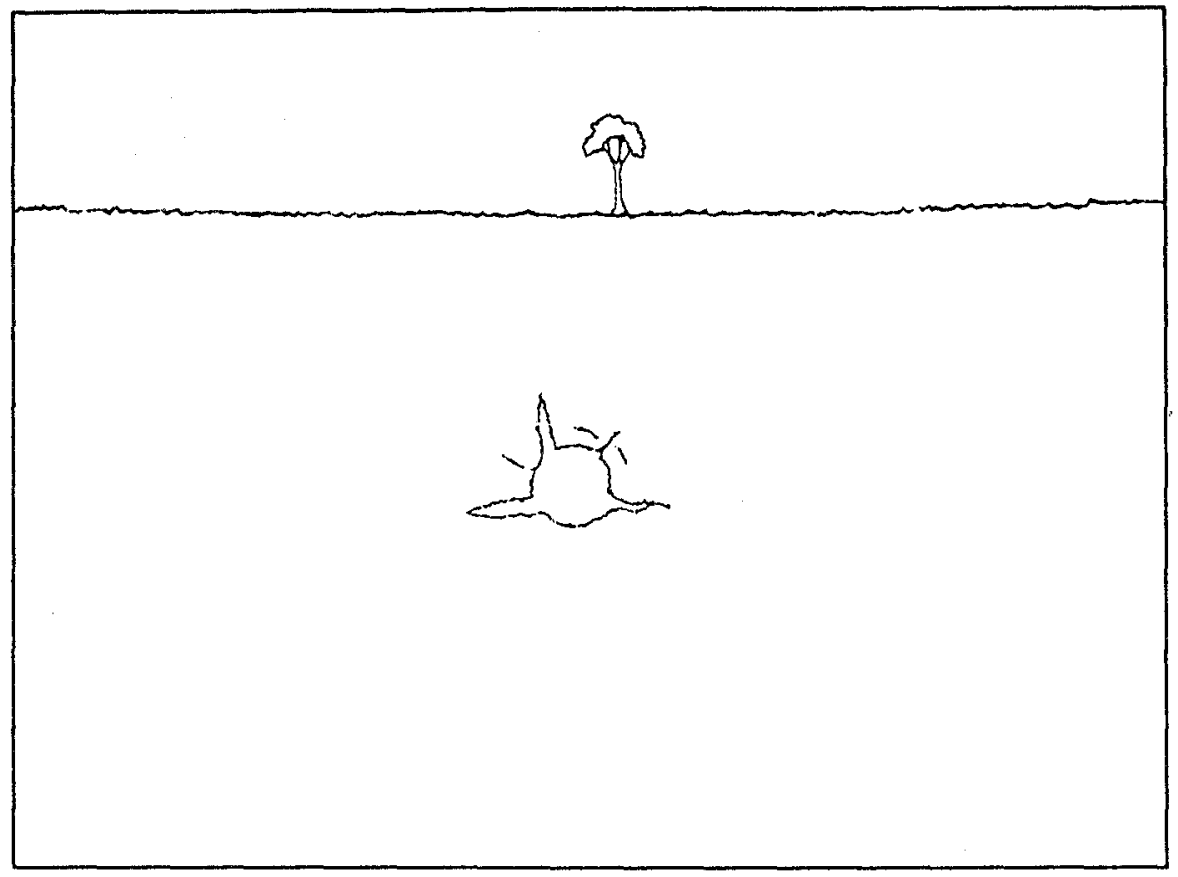

Figure 2. Halo effects allow most cavities to be detected deeper.

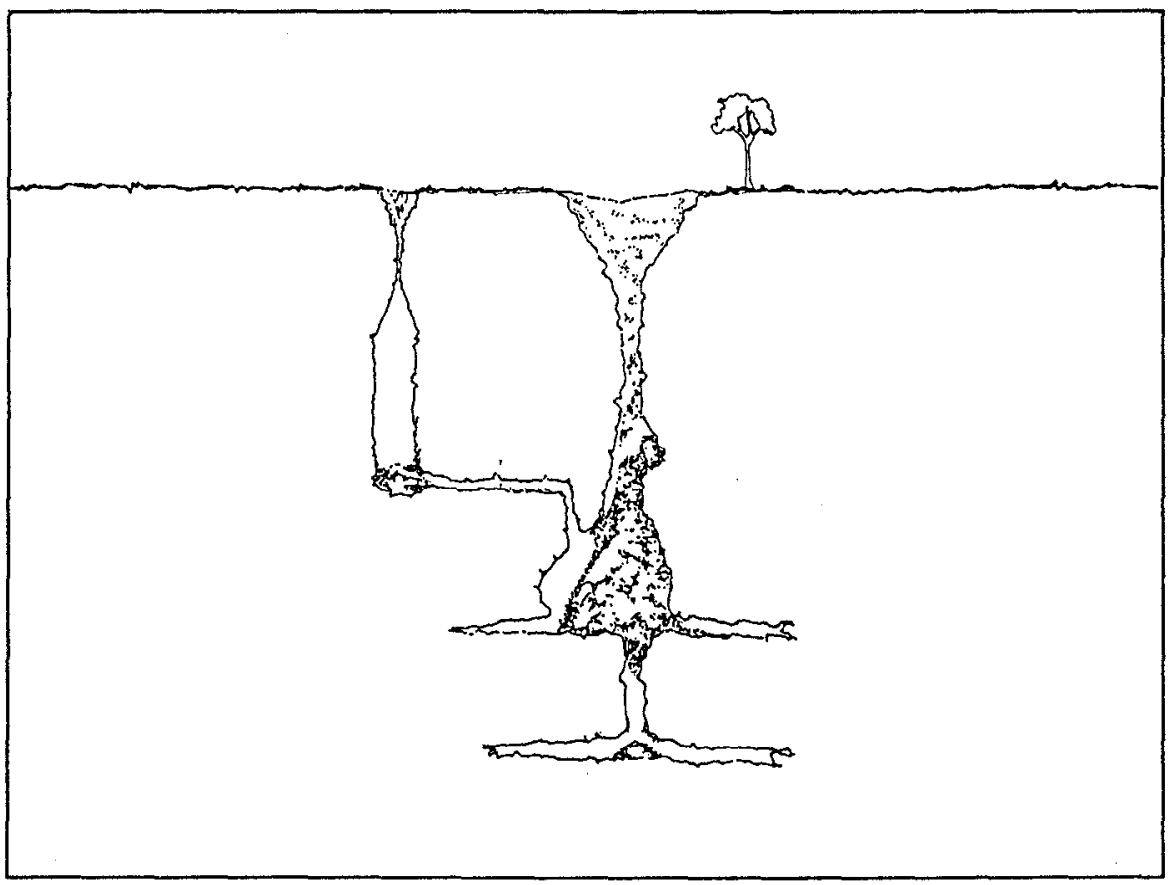

Figure 3. Most cavities are part of a complex cave system and can be detected at even greater depths. 
Because of these factors and the use of improved instrumentation and field techniques, the limits of detection have been significantly revised. "Spherical cavities" can now be detected to depths of up to 6 to 8 times their diameter and linear conduits up to 10 times their diameter by the microgravity method (Butler, 1980).

Two surface geophysical methods, electromagnetics and microgravity, were identified as the most likely candidates to successfully resolve the presence of karst features in this geologic setting.

\section{Electromagnetics}

Electromagnetics using a Geonics EM34 was selected because these measurements provide an excellent means of locating dissolution-enlarged joints. When employed in the vertical dipole mode, EM measurements are capable of detecting dissolutionenlarged joints. Figure 4 illustrates the response from a traverse over a vertical joint filled with clayey soil. To yield a characteristic response, the joint must have a width which is substantially less than the intercoil spacing of the instrument being used and must be filled with a material higher in conductivity than the surrounding materials. When the EM measurements are made at or greater than approximately two intercoil spacings from the vertical joint the instrument indicates the correct response for the homogeneous rock. As the measurement position approaches and passes over the joint, the response becomes a negative going anomaly as indicated in Figure 4 . When the coil spacing is centered over the joint, the lowest conductivity response is obtained, thereby indicating the joint location. In geologic situations where multiple joints occur, the response will obviously be more complex than that shown in Figure 4 but will generally show low or negative response in the EM measurements.

The electrical conductivity of the massive limestone is about $5 \mathrm{mmhos} / \mathrm{m}$ and the conductivity of the alluvium material infilling the joints is about 20 to $50 \mathrm{mmhos} / \mathrm{m}$ which yields a sufficient conductance (conductivity $x$ thickness) for dissolution-enlarged joints with a width of a few feet or more. Since the rock is essentially flat-lying, the joints will be nearly vertical. This is an ideal geologic environment in which to detect such features within the upper 100 feet by using EM34 measurements with a 10 meter and 20 meter coil spacing. 


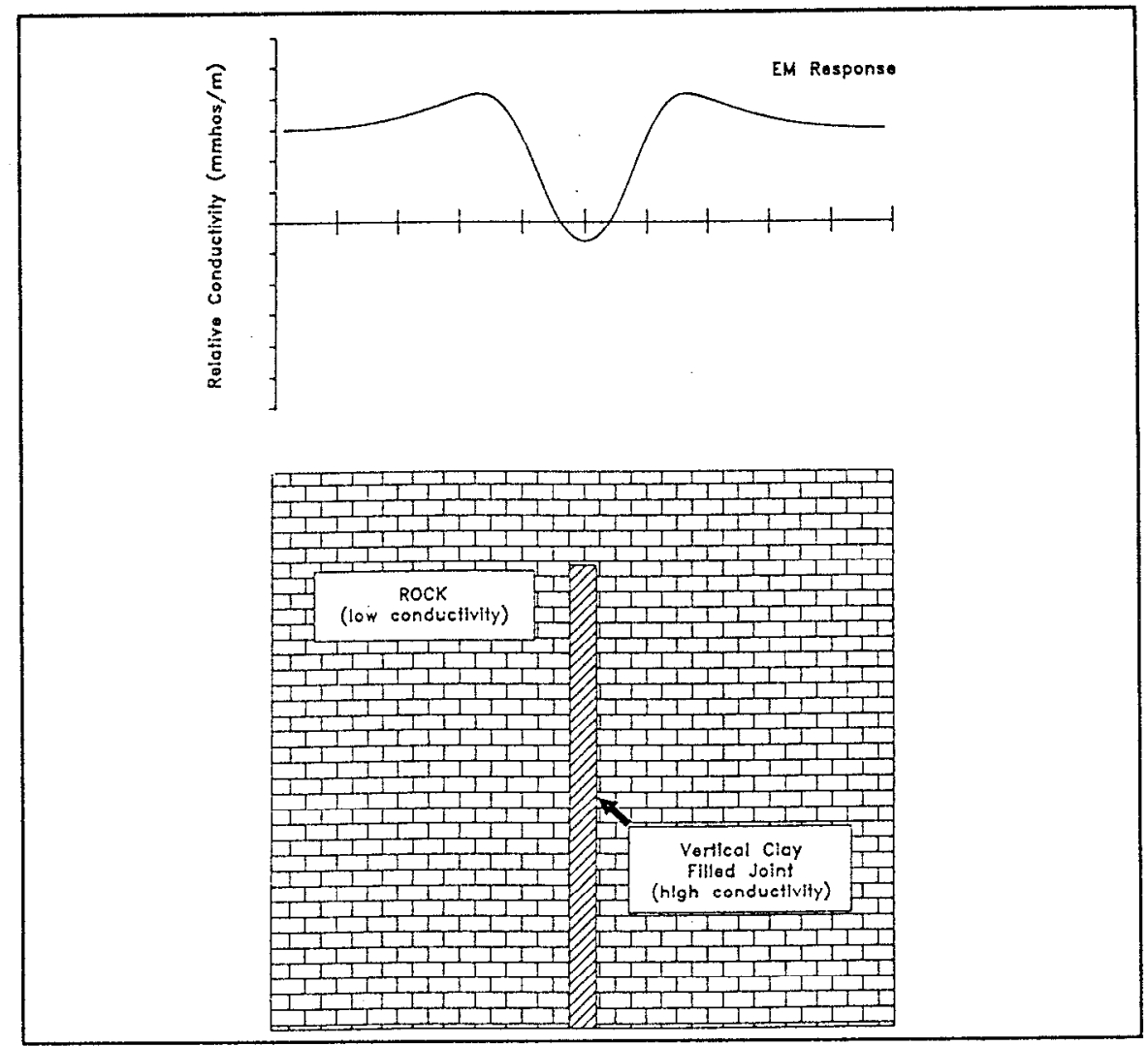

Figure 4. EM response over vertical joints filled with clayey soil.

Furthermore, data acquisition with EM34 measurements can be made relatively rapid ( 80 to 160 sets of measurements/day), depending upon the number of measurements made at each station, the distance between stations and the ease of access from station to station. The raw EM data plotted in a profile can be used to indicate the approximate locations of vertical dissolution-enlarged joints without any data processing. The exact location of the joints becomes more subjective if sample spacing is not sufficiently close to define the response or when the response becomes complex due to a number of closely spaced joints.

\section{Microgravity}

The basic scheme of gravity surveying is to determine the gravity values at many stations and then to correct these values for all known effects. Lateral variations or anomalies in the resulting residual gravity data can then be attributed to lateral variations in the densities of subsurface materials, i.e. caves, buried channels, structural causes, etc. A microgravity survey consists of making sensitive gravity measurements (at the microGal 
level $1 / 1000$ of a milliGal) at relatively closely spaced stations to detect subtle lateral changes in density. These anomalies are interpreted by creating geologically-consistent density models which produce the same gravity values as observed in the field data (Figure 5).

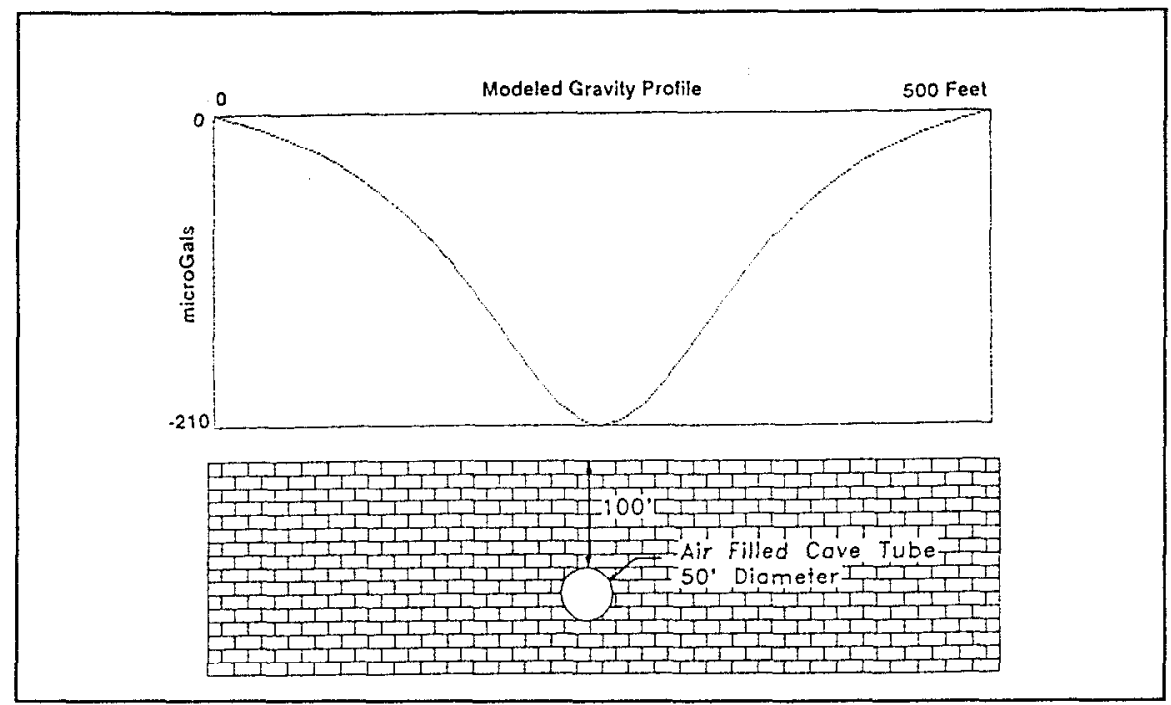

Figure 5. Modeled gravity anomaly over air-filled cave illustrating anomaly width versus target depth.

Microgravity was selected because it is the only surface geophysical method that will provide the location of karst feature regardless of their shape or fill material as long as there is a sufficient density contrast. The gravity method will respond to larger vertical dissolution-enlarged joint systems, as well as cave systems which are air or alluvium filled. Since the rock is generally massive, nearly horizontally bedded and topographic variations are small, this geologic environment is an excellent one for detection of karst features using microgravity.

Gravity data acquisition is much slower and more tedious to acquire than EM data (about 40 to 80 measurements/day) and can depend on noise conditions, the distance between stations and the ease of access from station to station. Furthermore, numerous corrections (earth tides, latitude, elevation, Bouguer slab density) and data processing are required to yield a simple Bouguer gravity anomaly. The gravity anomaly data are then displayed as profiles or contour maps. Interpretation of the data is usually done using simple geologic models. However, because of the non-uniqueness that occurs with all geophysical interpretations, these simple models may only approximate complex geologic conditions. 


\section{COMPLEMENTARY NATURE AND LIMITATIONS OF THE TWO GEOPHYSICAL}

METHODS

Gravity measurements will respond to both air and alluvium-filled joints and caves of sufficient size. However, as the density of the fill material approaches the density of the in-place rock, the anomaly tends to zero. Therefore, gravity is best used for karst features which are air-filled and provide a maximum density contrast or at least are filled with sufficiently lower density material.

EM measurements, on the other hand, are a function of electrical conductivity contrast and will respond to vertical joints of sufficient width (and caves) filled with alluvium regardless of the density of the material. However, as the electrical conductivity of the fill material approaches the electrical conductivity of the in-place rock the EM anomaly levels tend to zero.

While both methods have limitations, as do all methods of site characterization, the combination of gravity and EM measurements are complementary in their application to detecting and characterizing karst features under these conditions (what one may miss the other may detect).

\section{Use of Known Karst Features to Develop a Spatial Sampling Criteria}

Karst features including dissolution-enlarged joints and cavities are commonly observed in road cuts. Freeman (1968) identified linear paleokarst collapse features up to 1500 feet wide and 3 miles long and circular paleokarst collapse features up to 4,000 feet across with vertical displacements of up to 250 feet. Other features such as fractures and recharge areas (dolines) are found in the area along with joints and extensive lineaments observed in the aerial photography. Numerous caves have been identified and some have been mapped in detail with depths up to 500 to 600 feet. These features can be used to establish the spatial sampling criteria required to adequately detect and map these features (Benson and Yuhr, 1993). We have used a known large cave system to establish a sampling criteria for the detection and characterization of such features. Field tests were then run over two known karst sites; a paleokarst collapse; and a localized doline to provide some anomaly signature in the geologic setting. These features are representative of the variety of karst features in the area.

\section{LARGE CAVE SYSTEM}

A map of a cave system was used to estimate the magnitude and the lateral extent of its gravity anomaly. A cave which extends from the surface to a known depth of about 500 feet, has been extensively mapped by Veni (1980; Figure 6). 


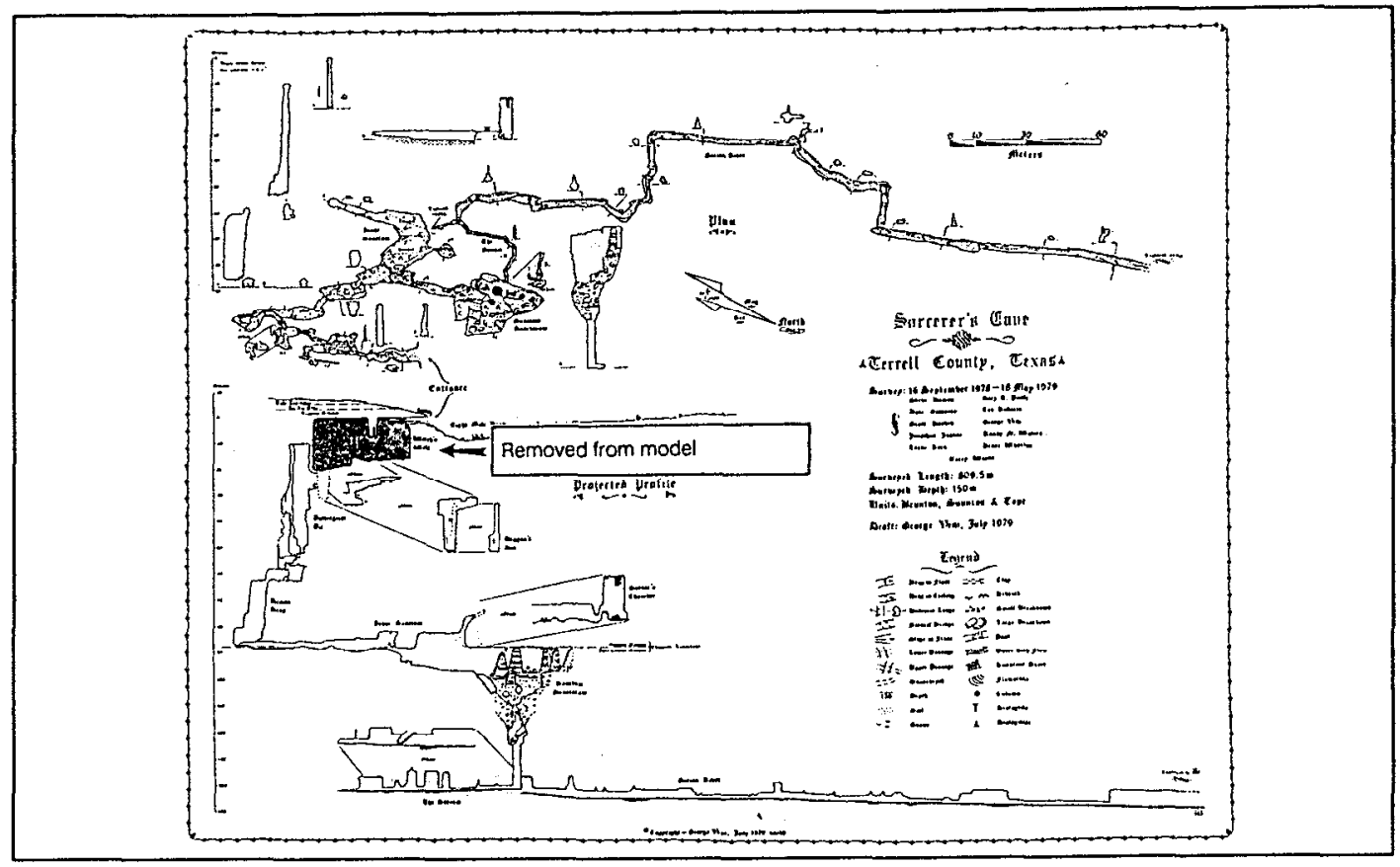

Figure 6. Map of local cave system (from Veni, 1980).

A simplified spatial gravity model of this cave was constructed by using three dimensional polygons to represent the major cave passages (the gravity program used was "GModel" by LaCoste \& Romberg). All large cave passages were entered into the model. Numerous smaller passages, which had been mapped were not included in the model. Furthermore, we recognize that all of the components of the cave system are never completely mapped, therefore, such a model will surely underestimate the gravity anomaly. This conservative gravity model of the cave indicates that the cave system (Figure 7a) provides a maximum gravity anomaly of about 150 microGal anomaly and has greater than a 30 microGal anomaly over a distance of about 300 feet. To be even more conservative, we have removed the large uppermost room of the cave in the model. This model results in a maximum anomaly of about 80 microGals and has greater than a 30 microGal response over an area of more than 200 feet (Figure $7 \mathrm{~b}$ ). We then assume that this even more conservative gravity model is typical of any recent cave development to depths of 100 to 500 feet. The paleokarst collapses identified by USGS would be expected to provide an even larger gravity response, based upon its observed lateral extent at the surface. 


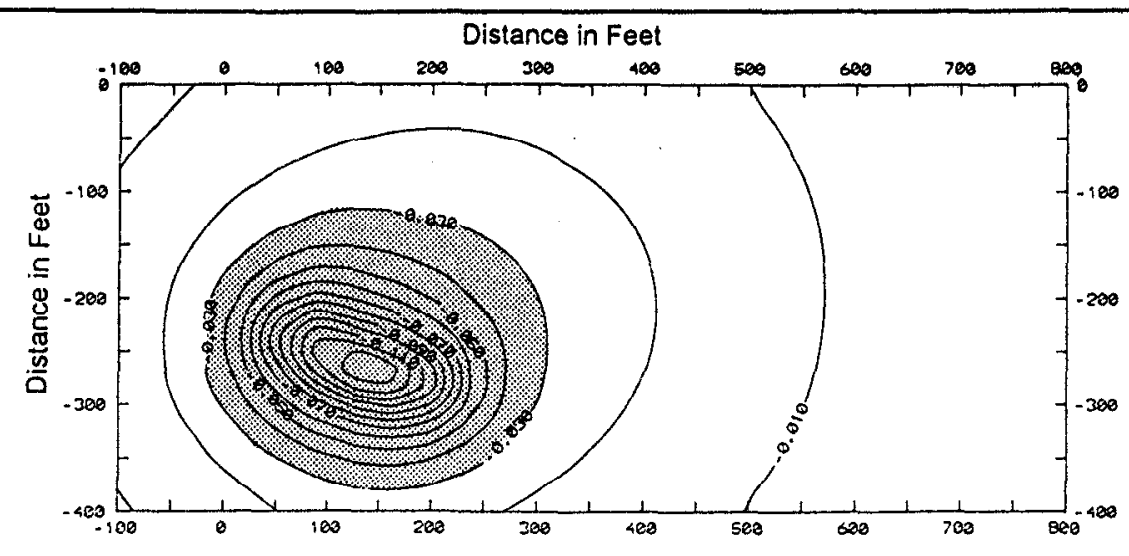

A. Maximum measureable anomaly of about 150 microGals over a local cave system. A 30 microGal anomaly extends over more than 300 feet.

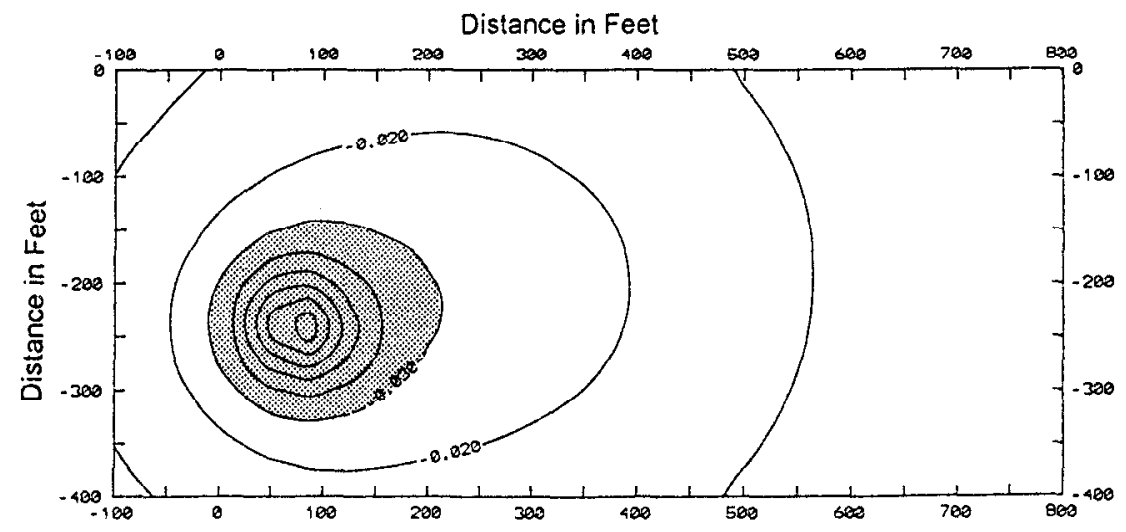

B. Maximum measureable anomaly of about 70 microGals with the largest and shallowest room removed from the system. A 30 microGal anomaly extends over more than 200 feet.

Values are shown in milligals.

Figure 7. Modeled microgravity anomaly over local cave system.

Based upon this very conservative model of the cave system, with a 30 microGals response extending over 200 feet, a 50 -foot station spacing was selected for the gravity measurements. A 50 -foot station spacing would yield 4 to 5 measurements over the 200-foot anomaly which is sufficient to define the shape of such an anomaly with a reasonable level of confidence. The 50-foot spacing would minimize the number of gravity stations (hence the cost of the survey) and yet, be sufficiently close together to adequately sample the shape of such an anomaly. A sensitivity of about 1 microGal and repeatability of about 5 microGals can be obtained under reasonable field conditions, therefore, the sensitivity of the survey method is more than adequate to detect such features. Features of interest at depths of 100 feet and greater will be well defined by the 
50-foot station spacing and the sensitivity of the survey method. At depths less than 100 feet, the gravity anomalies can be under-sampled by the 50 -foot station spacing.

While the 50-foot station spacing for microgravity measurements is adequate for detection of many karst features of interest, it is probably not small enough to adequately define single narrow fractures. The EM method, using an EM34 is better suited for this application. It is recognized that a station spacing of 10 feet would be more desirable for total detection and definition of vertical joints with EM measurements. However, a 50foot spacing will provide an adequate sampling to define a zone of significant dissolution or even a single dissolution feature if it were wide enough using EM34 measurements. Furthermore, the 50-foot spacing will generally provide some indications of the presence of smaller dissolution-enlarged joints by an erratic negative going response in the EM measurements.

\section{Field tests}

Field tests were run over two known karst features to check the methods and sampling criteria established.

\section{PALEOKARST COLLAPSE FEATURE}

A paleokarst collapse feature approximately 300 feet across was selected for tests. The perimeter of the site has limestone turned on-end, which is typical of the paleokarst collapse in the area mapped by USGS. A railroad cut exposes the north-end of the collapse, where dipping rock can be observed. A boring in the approximate center of the collapse feature indicated a graben-like displacement of about 150 feet.

A single west to east survey line 1500 feet long was established across the site. Both microgravity measurements and EM34 data were obtained along this line at a station interval of 50 feet. The profiles of the microgravity data and EM34 data over the collapse are shown in Figure 8 along with a conceptual model of site conditions. Both the EM34 and microgravity measurements correlate well with the lateral extent of collapse as indicated by the dipping limestone at the surface. 

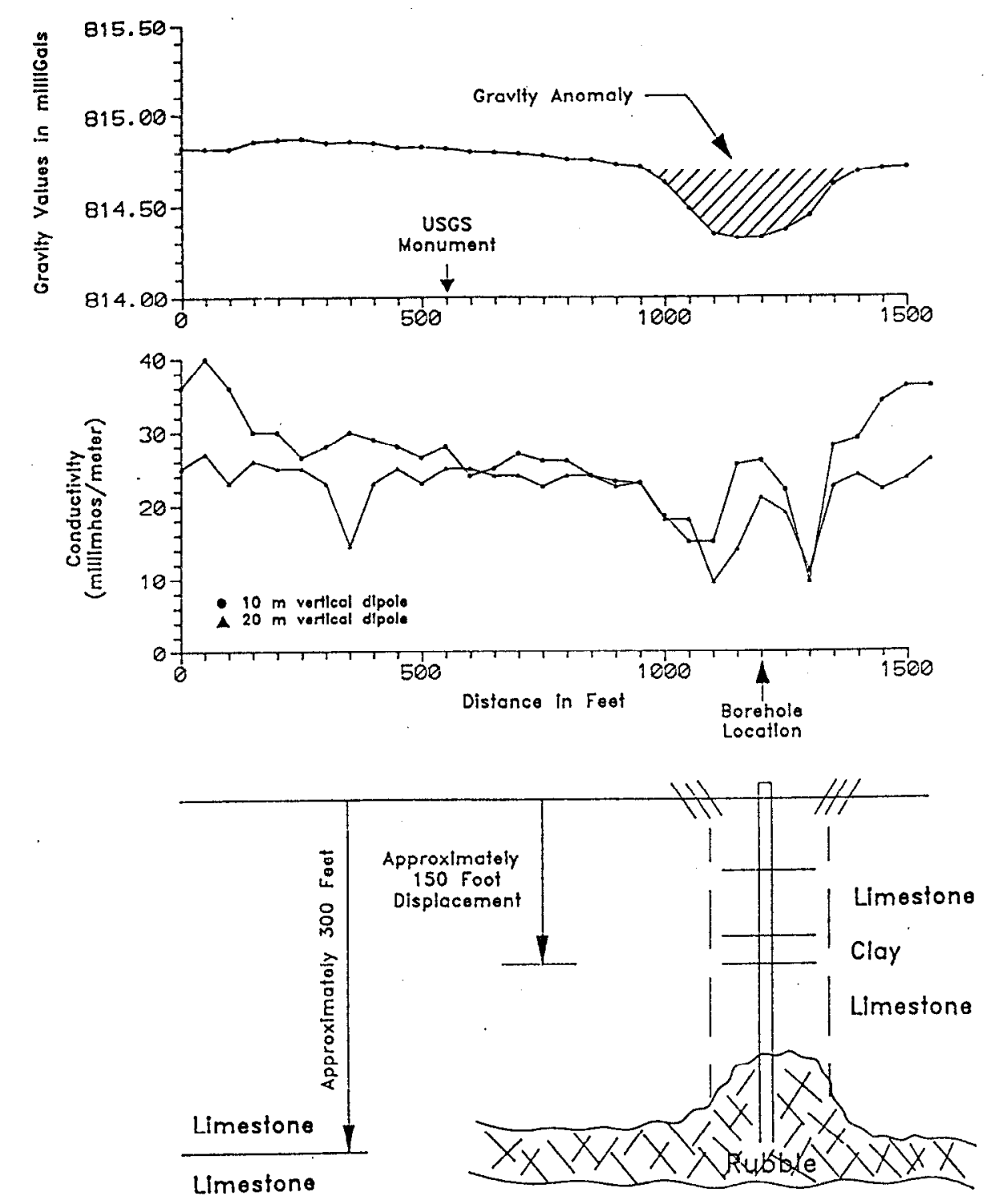

Figure 8. Electromagnetic and microgravity data over paleokarst collapse with conceptual geologic model.

The gravity data indicates a smooth and symmetrical anomaly of 400 microGals. A gravity model for the collapse consisting of a vertical shaft ( $300 \times 300$ feet) and 330 feet deep filled with alluvium (density contrast approximately $0.28 \mathrm{~g} / \mathrm{cc}$ ) provides a reasonable match to the field data (Figure 9). This agrees with the approximate depth of Miocene cave development described by USGS. 

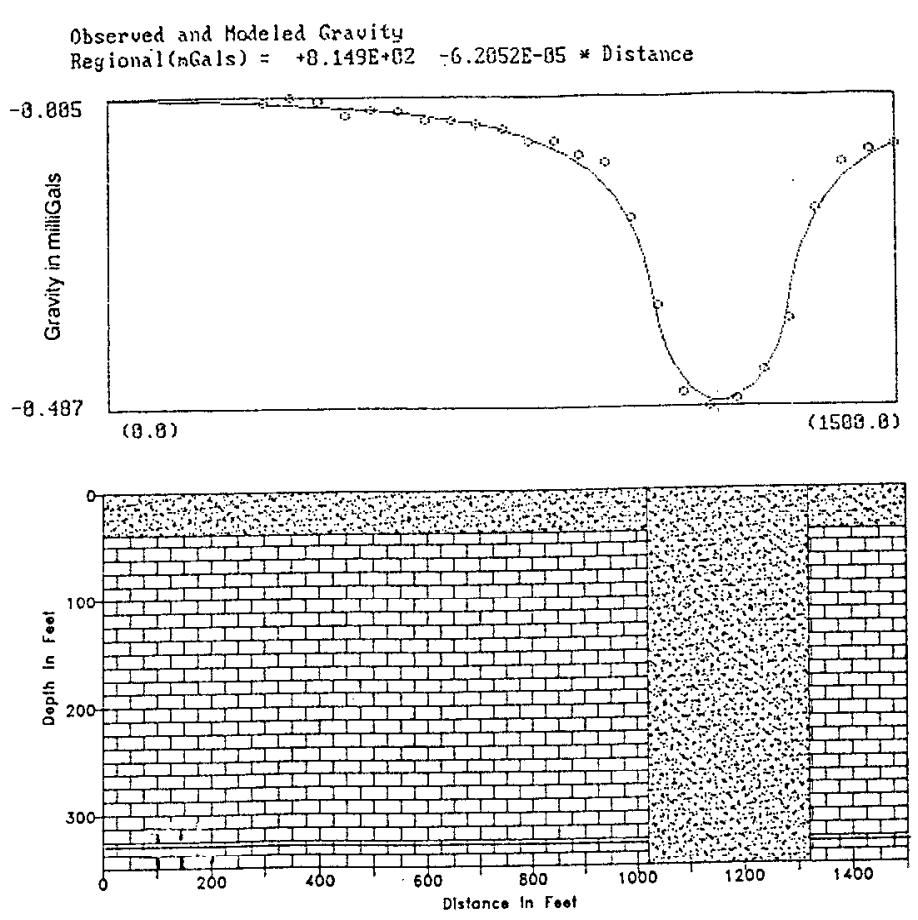

Figure 9. Gravity model of vertical shaft with actual field data.

The EM34 data (Figure 8) shows "low conductivity values" at both edges of the paleokarst collapse feature. These low conductivity values should occur when the feature or dissolution-enlarged joint is centered between the transmitter and receiver coils of the EM34. The EM34 data indicates slightly more conservative boundaries (about 200 feet wide) from center to center of the lowest conductivity values; this may be due to the station spacing not being optimized for the EM34 data. This EM data can be interpreted as a lateral discontinuity at the edges of the paleocollapse, which is causing a disruption of the normally horizontal currents generated by the EM system.

Since the paleokarst collapse is one of the smaller known paleokarst collapse features, we can conclude that the presence of paleokarst collapse should be easily mapped using EM and gravity measurements. In this example, the EM34 measurements detected the lateral boundary of the collapse feature but did not detect a conductivity contrast within the collapse feature itself. Microgravity measurements on the other hand, detected a distinct density contrast within the collapse feature with the lateral extent correlating with the boundaries observed at the surface. 
LOCALIZED DEPRESSION (DOLINE)

A circular depression, a doline karst feature about 500 feet in diameter, is an area of active surface water recharge into the rock with soil fissures and obvious evidence of soil piping. Field observations indicate a distinct depression along with a circular vegetation pattern, circular elevation changes, and relatively uniform periodicity of piping features on a circumference around the central portion of the site. Rock outcrops over much of the area, except for a thin veneer of alluvium. A fine grain soil cover is found at the center of the depression.

The borehole data from six boreholes (both geologic and geophysical logs) reveal very consistent conditions across the site with no displacement. Furthermore, there is no evidence for any karst features in any of these six borings or the geophysical and television logs from them.

A single line of microgravity and EM34 measurements was made along a 1,100 feet line oriented in an east to west direction which passed over the center of the feature. Initially both the EM34 (10- and 20-meter vertical dipole) and microgravity measurements were run at the 50-foot station spacing. The line was then re-run at a station spacing of 10 feet in the area of the depression.

The EM34 data spaced at 50-foot station interval indicates little change in conductivities across the site. Only a very subtle low conductivity is seen in the center of the depression (Figure 10). This line of data was then re-run over the center of the depression at a 10-foot station spacing in order to check for the presence of any smaller anomalies.

The EM34 data (10 and 20-meter coil spacing vertical dipole) at the 10-foot interval clearly indicates the presence of vertical clay-filled joint(s) (based upon the low and negative values) within the depression (Figure 11). The EM34 10-meter coil spacing data indicates the presence of multiple negative going values while the 20-meter coil spacing indicates a single-broad area of low and negative conductivities. At face value, the more erratic 10-meter coil spacing data may be an indication of the presence of a few shallow dissolution-enlarged joints, while the deeper data (20-meter coil spacing) indicates possibly a single dominant joint. The interpretation of the EM34 data at 20meter coil spacing must be taken as a simplified approximation since the 20-meter coil spacing, the station spacing used, and the fact that there are likely multiple shallow joints (EM34 10-meter coil spacing) can lead to a complex response which has no simple interpretation.

Clearly, the EM measurements made at a 50-foot interval have under sampled this anomaly. However, these karst features (vertical dissolution enlarged joints) are quite 
small and more subtle than those indicated at the paleokarst collapse feature. Although this feature was initially under sampled, the EM data at a 50-foot spacing did provided an indication of the presence of an anomaly. For further work in this geologic area, a 50foot station spacing can be maintained.

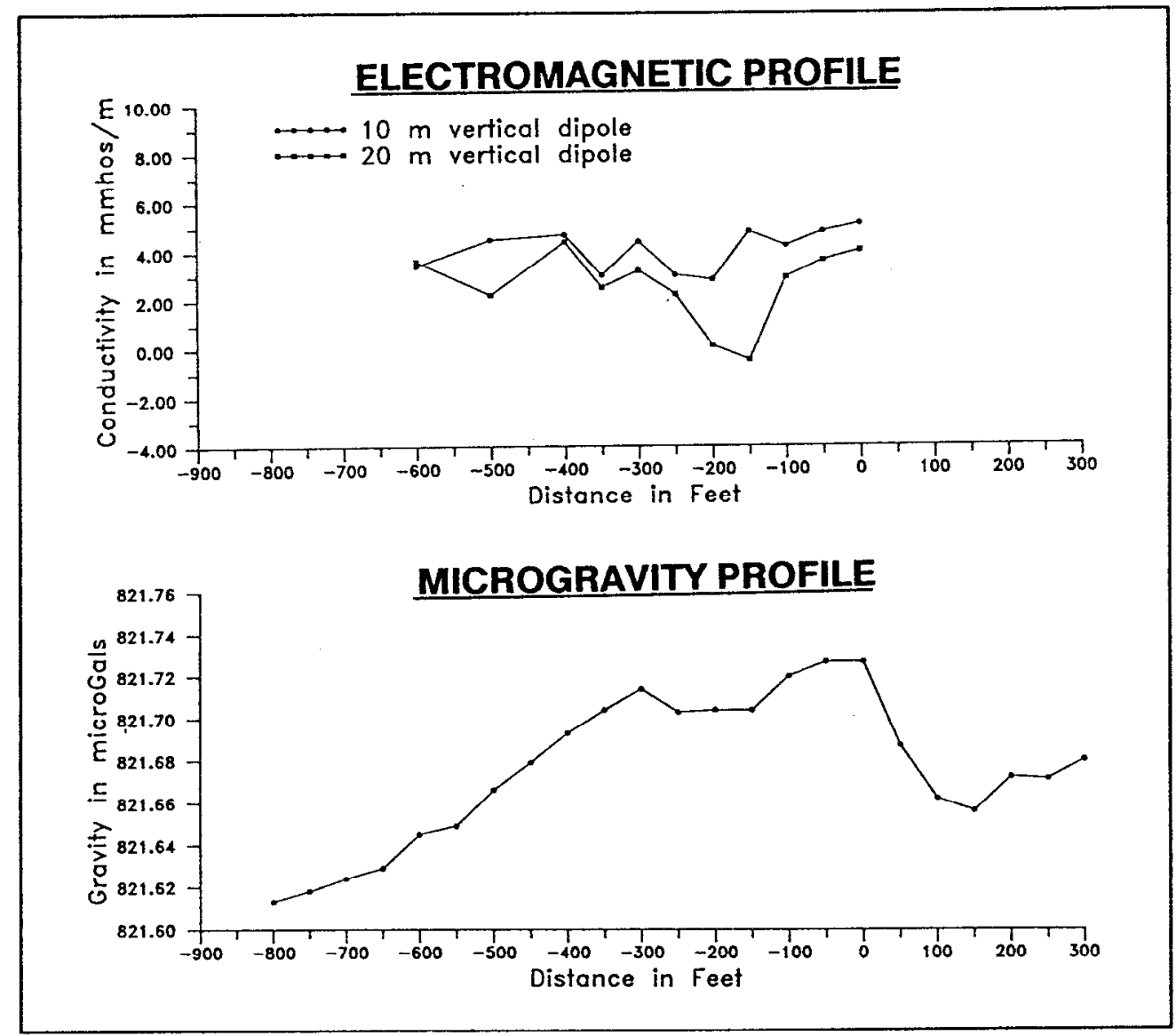

Figure 10. Initial electromagnetic and microgravity profiles over local depression using a 50 -foot station spacing.

The microgravity data at the 50-foot station spacing indicates two gravity anomalies (Figure 10). One gravity anomaly is located within the depression. This gravity anomaly has a magnitude of about 25 microGals. The second gravity anomaly of about 100 microGals occurs at the eastern end of the survey line well out of the depression.

Because the EM34 data was clearly under sampled the microgravity data was also rerun at a 10-foot station spacing in order to check the validity of the 50-foot data. In comparing the two data sets it appears that the 50-foot station spacing was quite adequate to define the overall anomalies at this site (Figure 11). 
West

East
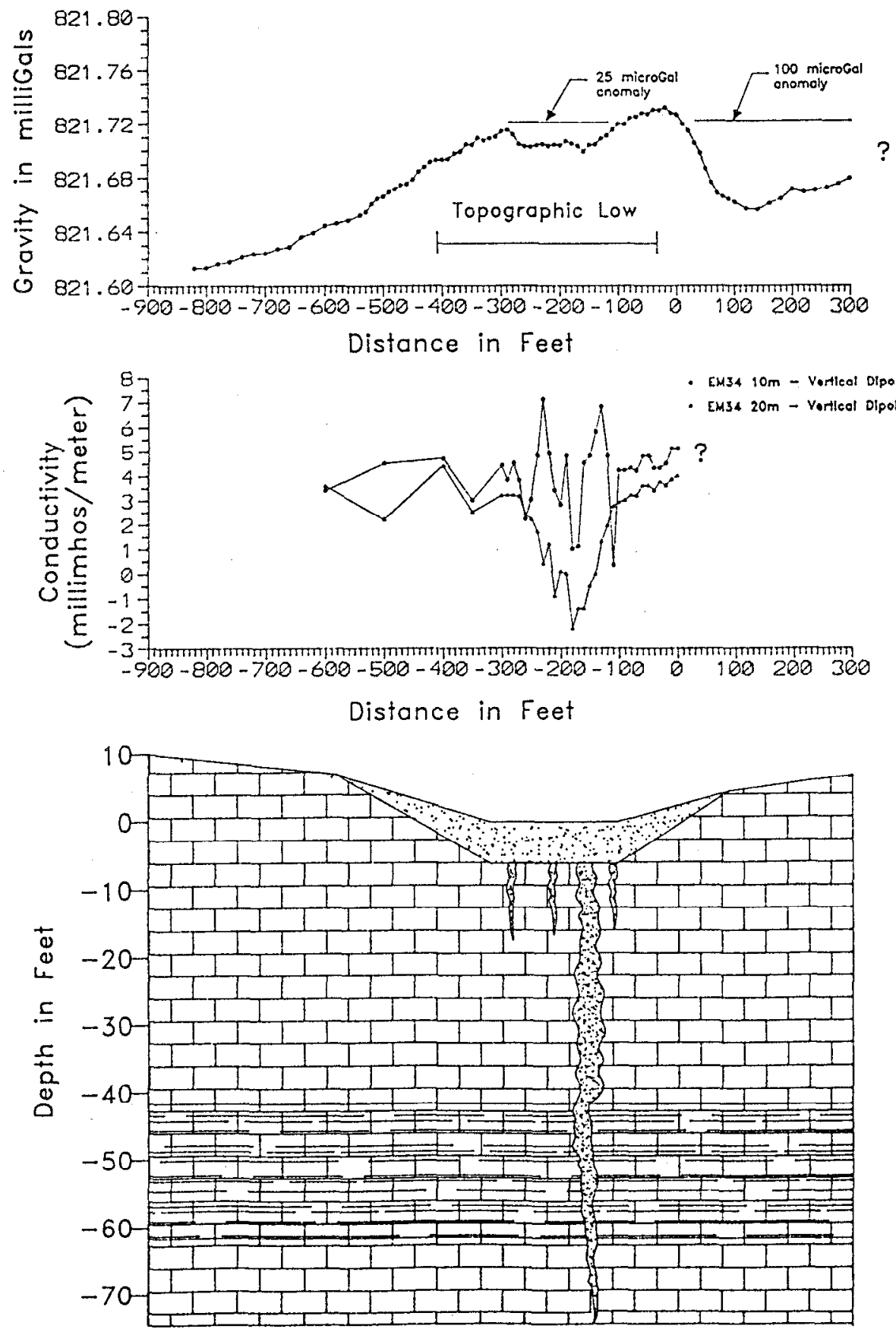

Figure 11. Electromagnetic and microgravity data over local depression (10-foot station spacing) with conceptual geologic model. 
The center of the depression is known to contain a thin veneer of soil 5 to 7 feet thick, based upon borings. An analytical gravity model of this lower density silt and clay soil cover overlying limestone produces about a 15 microGal anomaly (Figure 12). The remaining localized anomaly of about 10 microGals (within the 25 microGal anomaly) can be modeled by a single clay-filled joint. The location of the single major joint indicated by the gravity data and EM34 20-meter coil spacing data agree within \pm 10 feet.

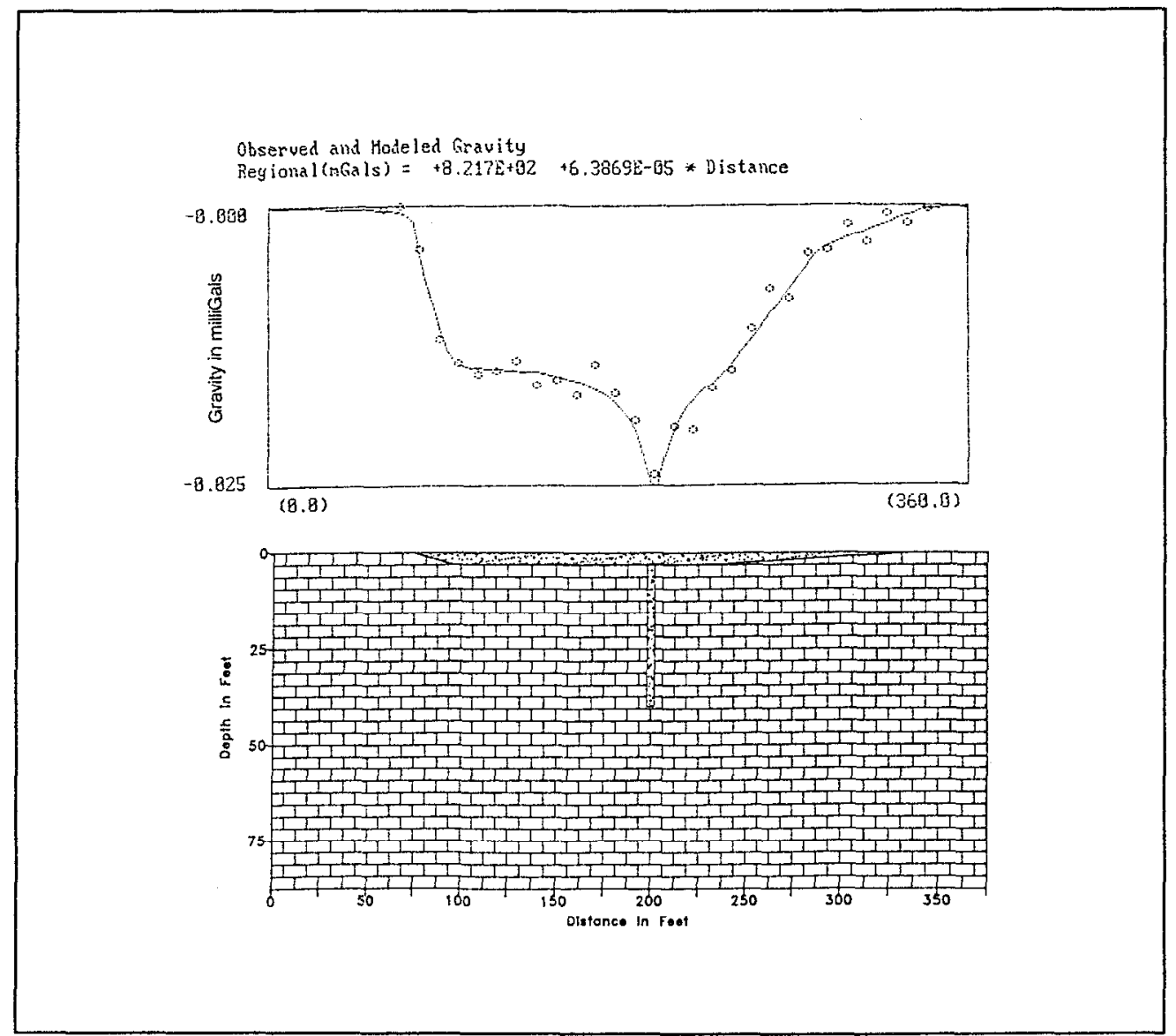

Figure 12. Gravity model of single vertical dissolutioned joint (alluvium-filled) with actual field data.

The gravity anomaly over the depression (25 microGals of which only 10 are probably due to dissolution-enlarged joints) is much less than might be expected. There is obviously not a large karst system directly under the depression based upon the existing microgravity data.

The larger gravity anomaly (100 microGals) to the east was unexpected. Unfortunately the gravity and EM lines did not extend eastward far enough to define the eastern 
boundary of this anomaly. Therefore, modeling was not done for this anomaly and further work will be required to define it.

This data can be used to create a conceptual cross sectional model of conditions at the doline showing enlarged joints which are allowing recharge to occur as shown in Figure 11. This interpretation is a first approximation based upon semi-quantitative assessment of the geophysical data but provides a reasonable conceptual model of site conditions.

In this field example, the microgravity data provides little indication of a karst feature, other than the possible single alluvial-filled joint. A station spacing of 50-feet adequately define the overall gravity anomaly, however, the very small, local anomaly (joint) modeled in Figure 12 would have gone undetected. The EM34 measurements, on the other hand, provided much more information at the 10-foot station spacing, indicating an area of fractures and/or dissolutioned enlarged joints.

\section{CONCLUSIONS}

The karst features of interest in this geologic setting were those which have undergone dissolution enlargement, such as vertical joints, zones of joints, paleokarst collapse and open cave systems. The normal "tight" joint systems were not of interest.

Two surface geophysical methods, electromagnetics and microgravity, were identified as the most likely candidates to successfully resolve the presence of karst features in this relatively uniform geologic setting.

EM measurements were primarily used to detect large joints which are sufficiently wide, filled with a conductive material and are in the upper 100 feet. Microgravity measurements were primarily used to detect both air and alluvium-filled joints and caves of sufficient size and with a sufficient density contrast at depths of 100 feet and greater.

While both methods have limitations, as do all methods of site characterization, the combination of EM and gravity measurements are quite complementary in their application to detecting and characterizing karst features under these conditions in that (what one may miss the other may detect).

An assessment of the spatial sampling and instrument sensitivities necessary to define the karst features of interest in this geologic setting was carried out using a known cave system. An estimate of the magnitude and the lateral extent of its gravity anomaly which was then used to select an optimum station spacing of 50 feet. 
Field tests were run over two known but significantly different karst features, one a paleocollapse with 150 feet displacement, another a doline of about 500 feet in diameter. Results from both sites indicate that the approach selected will detect any significant karst and even relatively small vertical joints as seen in the test data at the doline.

Using microgravity, features of interest at depths of 100 feet and greater will be well defined by the 50 -foot station spacing and the sensitivity of the method. At depths less than 100 feet, the gravity anomalies can be under-sampled by the 50 -foot station spacing.

Although, a 50-foot spacing for EM34 measurements will provide an adequate sampling to define a zone of significant dissolution or even a single dissolution feature if it were wide enough, smaller features will be under sampled.

It is clear that the EM and the gravity techniques are appropriate for detecting and characterizing karst features in this geologic setting. However, one of the key issues in planning and carrying out a geophysical survey, is developing a spatial sampling criteria. This criteria should be based upon an understanding of project objectives, a conceptual geologic model of site conditions and, if possible, existing data from the area.

\section{REFERENCES}

Benson, R. C. and L. Yuhr, 1993. Spatial sampling considerations and their applications to characterizing fractured rock and karst systems. Proceedings 4th Multidisciplinary Conference on Sinkholes and the Engineering and Environmental Impact of Karst, in Panama City, Florida, January 25-27.

Butler, Dwain K., 1980. Microgravity Techniques for Geotechnical Applications. U.S. Army Engineer Waterways Experiment Station, Miscellaneous Paper GL-80-13.

Davies, J. C., 1986. Statistics and data analysis in geology. John Wiley \& Sons, New York, New York, 646 p.

Fiseler, R. G., J. Jasek and M. Jasek (Eds.), 1978. An introduction to the Caves of Texas, Guidebook 19. National Speleological Society Convention, New Braunfels, Texas, $115 \mathrm{p}$.

Freeman, V. K. 1968. Geology of the Comstock-Indian Wells Area, Val Verde, Terrell and Brewster Counties, Texas. USGS Professional Paper 594-k, $26 \mathrm{p}$.

Veni, George, 1980. Sorcerer's Cave. The Texas Caver, v. 25, n. 1, pp 1-21. 